\title{
Craniovertebral Junction Koch spine - an unusual presentation treated with a novel approach: case report and review of literature
}

\author{
Bipul Kumar Garg*, Shrikant Pradeep Savant, Sumit Maheshwari
}

\begin{abstract}
Department of Orthopedics, Grant Medical College and Sir JJ Group of Hospitals, Mumbai, Maharashtra, India
\end{abstract}
Received: 21 February 2019

Accepted: 23 March 2019

\section{*Correspondence:}

Dr. Bipul Kumar Garg,

E-mail: garg.bipul@gmail.com

Copyright: () the author(s), publisher and licensee Medip Academy. This is an open-access article distributed under the terms of the Creative Commons Attribution Non-Commercial License, which permits unrestricted non-commercial use, distribution, and reproduction in any medium, provided the original work is properly cited.

\begin{abstract}
The retropharyngeal space lies in the posterior pharyngeal wall between the middle and deep layers of the deep cervical fascia. It extends from the base of the skull to the mediastinum and frequently serves as a conduit for spread of disease from the neck into the chest. Spinal tuberculosis is the commonest extra pulmonary manifestation of tuberculosis. Clinical findings of cervical tuberculosis includes neck pain, restricted neck movements, quadriparesis, radicular manifestations, kyphosis, and sensory disturbance. It should be suspected in an adult person who presents with a destructive lesion of the cervical vertebra and retro-pharyngeal mass. Early diagnosis and treatment are necessary to prevent the serious complications of the disease. We present here a 46 years old female who presented to a tertiary care setup with acute onset dyspnea and quadriplegia with bladder bowel involvement managed with trans oral incision and drainage of retropharyngeal abscess followed by posterior occipitocervical fusion supplemented with Anti Koch Therapy with a good follow up.
\end{abstract}

Keywords: Retropharyngeal space, Abscess, Tuberculosis, Cervical vertebra

\section{INTRODUCTION}

Tuberculosis (TB) remains an important disease condition in many developing countries of the world, especially in people below the age of 20 years. Its incidence is also increasing in the developed countries as a result of the emergence of HIV/AIDS and increase in immigrant populations.

Skeletal tuberculosis constitutes 3-5\% of all cases of TB and $10-15 \%$ of extra-pulmonary $\mathrm{TB}^{1}{ }^{1} \mathrm{~TB}$ spine is the most common form of skeletal TB. It is the most dangerous manifestation of TB due to involvement of the spinal cord and the resultant neurological impairment.

More so its co-existence with retropharyngeal abscess is rarer. Retropharyngeal abscess results from suppuration of retropharyngeal lymph nodes in patients with upper respiratory tract infection or from traumatic perforation of the pharynx or upper esophagus by a foreign body. If the abscess compresses the larynx and upper trachea, symptoms of upper airway obstruction develop. Spinal tuberculosis (Pott's disease) the most common form of skeletal TB is considered the most dangerous because involvement of the spinal cord results in neurological impairment. Lumbar and thoracic regions are more often involved, whereas the incidence of cervical involvement is 2 to $3 \%^{1,2}$

The neurological deficit occurring with tuberculous spondylitis either due to cold abscess, granulation tissue, necrotic debris and sequestrae from bone or the intervertebral disc tissue, and occasionally vascular thrombosis of the spinal arteries. ${ }^{3}$ Here we present a case of a $46 / \mathrm{F}$ who presented to a tertiary care centre with acute onset quadriplegia with dyspnea diagnosed as a case of C1-C2 Koch spine with Retropharyngeal abscess managed with transoral incision and abscess aspiration 
followed by posterior decompression and fixation supplemented with anti Koch therapy with subsequent improvement in neurology over a 6 month follow up.

\section{CASE REPORT}

A 46 years old female presented to the Accident and Emergency Department of a tertiary care hospital with acute onset dyspnea and inability to move all four limbs. As derived from the relative, she had history of neck pain and restricted neck movements since 8 weeks gradually progressing in intensity to the current state with appetite loss.

On examination the patient had bilateral upper neck swelling with tenderness with no cervical lymphadenopathy. Examination of the oral cavity shows anterior displacement of the posterior pharyngeal wall with congested mucosa. Patient had MRC grade 0 power in all four extremities with exaggerated reflexes. The patient was stabilized in a Philadelphia Collar. Since, the patient was not able to maintain oxygen saturation, she was immediately shifted to the Intensive Care Unit, intubated with an endotracheal tube and put on a ventilator for breathing assistance. The patient also had spontaneous passage of urine and stool indicating a bladder bowel involvement. Vitals were monitored and a nasogastric tube was inserted for feeds and medications. An urgent MRI cervical spine (Figure 1) was done showing - Changes suggestive of spondylodiskitis at the occipito-atanto-axial level with adjacent abnormal soft tissue more on right side with presenting granulation tissue/abscess causing thecal sac compression suggestive of Koch involvement along with a C2 fracture with anterior displacement of Dens. CT Cervical spine was done to note morphology of the affected vertebrae correlated with the MRI findings. An all routine hematological workup was done which revealed lymphocytosis and a raised erythrocyte sedimentation rate and $\mathrm{C}$ reactive protein levels. The patient was planned for trans oral incision and aspiration of the abscess followed by posterior stabilization of the affected vertebrae with fixation. The patient was given supine position and general anesthesia was administered. The ENT Surgical team performed a trans oral incision and $10 \mathrm{ml}$ straw colored fluid was drained which was immediately sent for gram staining, acid fast smear, culture and sensitivity and GeneXpert testing. The patient was then flipped into prone position for the posterior fixation with Occipito-cervical fusion procedure with the help of fluoroscopy (Figure 2).

The patient was shifted back to the Intensive Care Unit post operatively and was extubated after monitoring of the saturation levels and other vitals.

Patient was started on all 4 limb physiotherapy followed by wheelchair mobilisation in a Philadelphia collar.

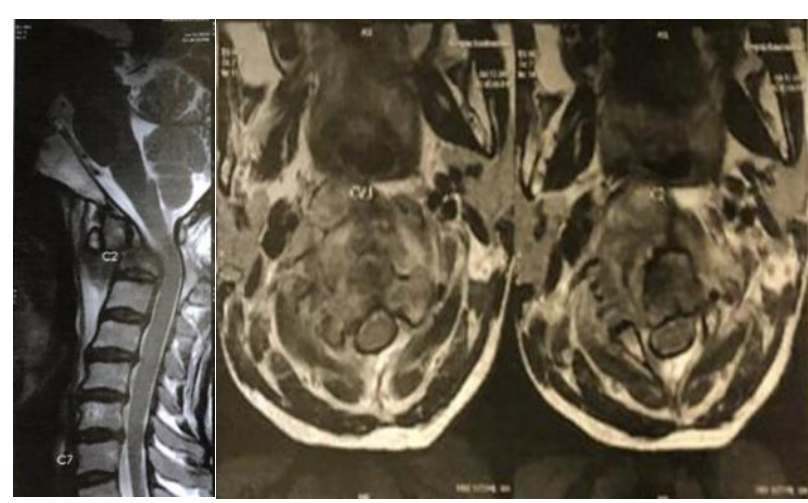

Figure 1: Pre operative MRI saggital and axial images showing spondylo-diskitis at the occipito-atlanto-axial level with adjacent abnormal soft tissue more on right side with presenting granulation tissue/abscess causing thecal sac compression suggestive of Koch involvement along with a $\mathrm{C} 2$ fracture with anterior displacement of Dens.

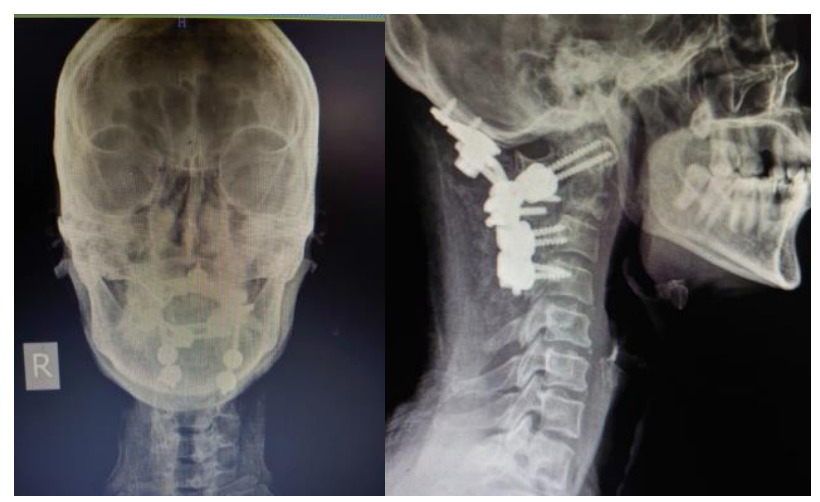

Figure 2: Post operative $\mathrm{X}$-ray showing fixation with occipito cervical fusion.

Two days later, the result of the smear came positive for acid fast bacilli and GeneXpert tested positive for acid fast bacilli with no rifampicin resistance and accordingly the patient was started on anti Koch therapy (HRZES). Gradually there was improvement in the power of the patient during the 2 week stay with bilateral lower limbs progressing to MRC grade 3 power and upper limbs progressing to MRC grade 4 power and normalization of upper limb and lower limb reflexes.

\section{DISCUSSION}

Retropharyngeal tuberculous abscess is a rare presentation of the disease even in the presence of extensive pulmonary tuberculosis. ${ }^{4}$ Sometimes, retropharyngeal tuberculous abscess causing stridor and threatening respiratory obstruction may be the only manifestation. ${ }^{5}$ The sites of spinal involvement with tuberculous spondylitis are paradiscal lesion, which is the most common site, central body lesion, anterior type in the anterior part of the vertebrae, appendicular type in the pedicle, lamina, transverse process and articular type in the posterior inter-vertebral joint. ${ }^{6,7}$ 
Tuberculous retropharyngeal abscess in adults is usually secondary to tuberculous involvement of cervical spine ${ }^{8 .}$ The probable route of spread of tuberculosis to retropharyngeal space is via the lymphatic to a persistent retropharyngeal lymph node. Rarely, the abscess may be due to hematogenous spread from pulmonary tuberculosis or tuberculosis elsewhere. ${ }^{9}$ Tuberculous infection causes destruction, caseation, and necrosis of vertebrae or may present as an abscess. The abscess may remain close to the vertebra and present on the radiograph as pre vertebral or Para vertebral abscess or it may move distally along the tissue planes to present as cold abscess. ${ }^{6,10}$ A delay in diagnosis and treatment can increase the risk of complications, including a spontaneous rupture of the abscess that can lead to trachea-bronchial aspiration or stridor secondary to laryngeal edema. Early diagnosis is also essential in order to prevent the onset or progression of the neurological sequel of Pott's disease. ${ }^{11}$ A retro-pharyngeal abscess can be drained safely via a trans-oral route or by an external route. ${ }^{12}$ It is well accepted that if the spine is stable and there is no neurological deficit, or minimal neurological signs, anti tuberculosis drug therapy and conservative neck stabilization should be the initial treatment. If neurological signs are prominent on patient admission or develop later, or if there is cervical instability or significant degree of subluxation, then surgical debridement and stabilization are indicated. ${ }^{13,14}$

\section{Funding: No funding sources Conflict of interest: None declared \\ Ethical approval: Not required}

\section{REFERENCES}

1. Fang D, Leong JC, Fang HS. Tuberculosis of the upper cervical spine. The Journal of bone and joint surgery. British volume. 1983;65(1):47-50.

2. Govender S, Ramnarain A, Danaviah S. Cervical spine tuberculosis in children. Clin Orthop Related Res. 2007;460:78-85.

3. Jain AK, Kumar S, Tuli SM. Tuberculosis of spine (C1 to D4). Spinal cord. 1999;37(5):362.

4. Melchor MD, Domingo CC, Monge RJ, Mariño JE, Ontañon MM. Tuberculous retropharyngeal abscess in an HIV patient. Report of a case. Acta Otorrinolaringologica Espanola. 1993;44(6):467-70.

5. Carroll N, Bain RJ, Tseung MH, Edwards RH. Tuberculous retropharyngeal abscess producing respiratory obstruction. Thorax. 1989;44(7):599600.

6. Hsu LC, Leong JC. Tuberculosis of the lower cervical spine (C2 to $\mathrm{C} 7$ ). A report on 40 cases. The Journal of bone and joint surgery. $\mathrm{Br} \mathrm{Vol}$. 1984;66(1):1-5.

7. Travlos J, Du Toit G. Spinal tuberculosis: beware the posterior elements. The Journal of bone and joint surgery. Br Vol. 1990;72(4):722-3.

8. Mathur NN, Bais AS. Tubercular retropharyngeal abscess in early childhood. The Indian Journal of Pediatrics. 1997;64(6):898-901.

9. Rice DH, Dimcheff DG, Benz R, Tsang AY. Retropharyngeal abscess caused by atypical mycobacterium. Arch Otolaryngol. 1977;103(11):681-4.

10. Nussbaum ES, Rockswold GL, Bergman TA, Erickson DL, Seljeskog EL. Spinal tuberculosis: a diagnostic and management challenge. Journal of neurosurgery. 1995;83(2):243-7.

11. Neal SL, Kearns MJ, Harris JP, Seelig JM. Manifestations of Pott's disease in the head and neck. The Laryngoscope. 1986;96(5):494-7.

12. Raj TB, Zarod AP. Acute non-tuberculous retropharyngeal abscess in adults (case reports of three patients). The Journal of Laryngology \& Otology. 1985;99(12):1297-300.

13. Cary ME, Infections of the spine \& spinal cord In: Youmans JR, ed. Neurological Surgery. 4th edn, vol, 5. Philadelphia. WB Saunders, 1996;3:270-304.

14. Behari S, Nayak SR, Bhargava V, Banerji D, Chhabra DK, Jain VK. Craniocervical tuberculosis: protocol of surgical management. Neurosurgery. 2003;52(1):72-81.

Cite this article as: Garg BK, Savant SP, Maheshwari S. Craniovertebral Junction Koch spine - an unusual presentation treated with a novel approach: case report and review of literature. Int J Res Orthop 2019;5:52931. 